\title{
COERÊNCIA E EFICÁCIAS NA COMUNICACÃO E NO RELACIONAMENTO DA TIM COM SEUS CLIENTES ATRAVÉS DO CANAL FACEBOOK
}

\author{
Ana Paula Rodrigues Ferro ${ }^{1}$
}

\begin{abstract}
RESUMO
Atualmente, e mais que nunca, saber se posicionar e se comunicar nas mídias e plataformas digitais pode causar grandes impactos para uma figura ou organização sejam elas boas ou ruins. Nesse sentido, seguir as etiquetas e os protocolos da comunicação coesa e coerente é fundamental para se atingir o sucesso almejado. Por essa razão, neste escrito, será analisado casos pontuais de interação via mídia digital (rede social facebook) entre a organização TIM e seus clientes, no intuito de compreender como e de que forma essa comunicação se materializa. Também, será apresentada a caracterização desta empresa junto ao mapeamento dos conflitos notados para propor um plano de intervenção.
\end{abstract}

Palavra-Chave: Comunicação Institucional; Redes Sociais e Comunicação; Relacionamento com o Cliente; Coerência e Eficácia.

\begin{abstract}
Today, and more than ever, knowing how to position and communicate on digital media and platforms can have major impacts for a figure or organization whether they are good or bad. In this sense, following the labels and protocols of cohesive and coherent communication is fundamental to achieve the desired success. For this reason, in this writing, it will analyze specific cases of interaction via digital media (social network facebook) between the TIM organization and its customers, in order to understand how and how this communication materializes. Also, the characterization of this company will be presented with the mapping of the conflicts noted to propose an intervention plan.
\end{abstract}

Keywords: Keyword: Institutional Communication; Social Networks and Communication; Relationship with the Client; Coherence and Effectiveness.

\section{RESUMEN}

Hoy en día, y más que nunca, saber posicionarse y comunicarse en medios y plataformas digitales puede tener grandes impactos para una figura u organización ya sean buenas o malas. En este sentido, seguir las etiquetas y protocolos de comunicación cohesiva y coherente es fundamental para lograr el éxito deseado. Por este motivo, en este escrito, se analizarán casos concretos de interacción a través de medios digitales (red social facebook) entre la organización TIM y sus clientes, con el fin de entender cómo y cómo se materializa esta comunicación. Asimismo, se presentará la caracterización de esta empresa con el mapeo de los conflictos señalados para proponer un plan de intervención.

Palabra clave: Comunicación Institucional; Redes Sociales y Comunicación; Relación con el Cliente; Coherencia y Eficacia.

\footnotetext{
${ }^{1}$ Bacharel em Administração e Recursos Humanos, licenciada em Letras (port-ing-esp) e Pedagogia, Mestre em Comunicação e Inovação. Pós-graduada em Gestão e Marketing Digital, MBA em Propaganda, Marketing e Comunicação Integrada, MBA em Gestão Empresarial, Especialista em Metodologia do Ensino de Línguas e Literaturas, Especialista em Educação e Novas Tecnologias. Email: paula_verani@hotmail.com
} 


\section{INTRODUÇÃO}

Este escrito tem como gatilho, para início do diálogo, a apresentação da caracterização da empresa TIM, bem como sua história e feitos. No Brasil, desde 1995, a TIM é a terceira maior empresa de telefonia móvel do país, com faturamento de 184 milhões de reais e 63,9 milhões de clientes. Como subsidiária da Telecom Itália, possui cerca de 10000 funcionários no Brasil. Com sede no Rio de Janeiro, está presente em todos os estados do país por meio de lojas, call centers e escritórios corporativos.

Atualmente, a companhia é uma das líderes do setor de telecomunicações no país e é responsável por, aproximadamente, 60 milhões de clientes brasileiros e atua em mais de 2,5 mil cidades com sua cobertura 4G. Oferta telefonia móvel, fixa e acesso à internet via modem, tablet, celular, além da ultra banda larga fixa, sendo serviços que fazem parte do portfólio inovador da TIM.

A operadora possui um acentuado estilo empresarial e é fato que a maioria de seus serviços são mais voltados a clientes adultos ou pessoas jurídicas. A TIM foca no segmento de telefonia móvel e fixa, além de assinatura de TV, mas exploraremos a oferta de telefonia móvel, já que este setor envolve a oferta de serviços para celulares e aparelhos que possuem a característica de receber e realizar ligações, além de permitir conectividade.

A telefonia móvel possui a característica de cobrança proporcional a utilização do serviço, havendo planos pré-pagos e pós-pago: no pré-pago é necessário a adição de créditos antes da utilização dos serviços, enquanto o pós-pago o usuário paga a fatura após o uso mensal dos serviços.

Nos últimos anos, a fim de atender uma demanda crescente do mercado nacional, a empresa intensificou sua atuação no segmento de ultra banda larga, serviço sob o guarda-chuva da operação de telefonia fixa.

O reposicionamento da infra-estruturar do $4 \mathrm{G}$ ao invés da melhoria do 3G, tornou a empresa mais atrativa para os usuários que buscam melhor serviço no pacote de dados. Esse posicionamento diferenciado da TIM garantiu a ela uma participação acima da média no segmento mais rentável do setor (móvel), além da melhora gradual em seus níveis de qualidade e cobertura, contribuindo de maneira determinante para a diminuição do legado problemático da companhia. 
Outro posicionamento e lema da empresa é o de evoluir de uma marca "barata" para uma operadora de qualidade, capaz de competir com sucesso também no segmento de alto valor.

Portanto, serão abordados como ocorre a comunicação e o relacionamento da TIM com seus clientes através do canal de atendimento facebook. Para isso, foram utilizados conteúdos referentes ao Composto de Marketing Digital e Mídias e Sociais Marketing, Conhecimento, Informação e Comunicação em Tempos de Globalização, como fonte para discorrer e ampliar a visão do leitor sobre o assunto em questão, além de dissertar sobre a relação da comunicação e mídias digitais com o marketing.

\section{SITUAÇÃO ATUAL DA EMPRESA TIM}

A empresa de telefonia TIM tem uma representatividade econômica muito significativa em nosso país no ramo de telecomunicação, contudo sua reputação nas mídias digitais como Reclame Aqui, Google Avaliação e até nos próprios canais de comunicação da organização, tais como facebook e site oficial, é bastante negativa. Por essa razão, surgiu o interesse em entender como se dá a relação da comunicação e o comportamento desta empresa com seus clientes, especialmente no canal facebook.

Cabe ressaltar que a TIM dispõe de diversos recursos e canais de comunicação e interação com os clientes, além dos citados, mas enfrenta grandes problemas na eficácia dessa comunicação e resolução dos problemas apontados neste âmbito, haja vista a alta proporção de reclamações no Reclame Aqui.

A empresa dedica esforços de segmento na oferta de telefonia pós-pago, pois, para ela, o serviço pré-pago é menos rentável, já que este público não possui vínculos contratuais com a operadora, tornando mais incerta a receita futura da empresa e, consequentemente, seu fluxo de caixa limita a disponibilidade de investimentos que podem ser realizados.

Dessa forma, há o incentivo, por parte das empresas de telecomunicação, de não reduzirem os preços no segmento pré, a fim de não fomentar a migração dos seus clientes do pós-pago para esses planos. Essa ação pode impactar na qualidade e no interesse da empresa se relacionar com esse público específico (o pré-pago) que é o alvo do nosso estudo. 
Para reforçar seu marketing relacional, a TIM recorre a personalidades de sucesso como a cantora Isa (negra, jovem, comunicativa, desinibida, animada, talentosa e empoderada), como cartão postal da empresa, para se comunicar visualmente, através de ideias afirmativas e positivas com seu público, que na maioria é jovem e de classe baixa.

Imagem 1. Propaganda da TIM

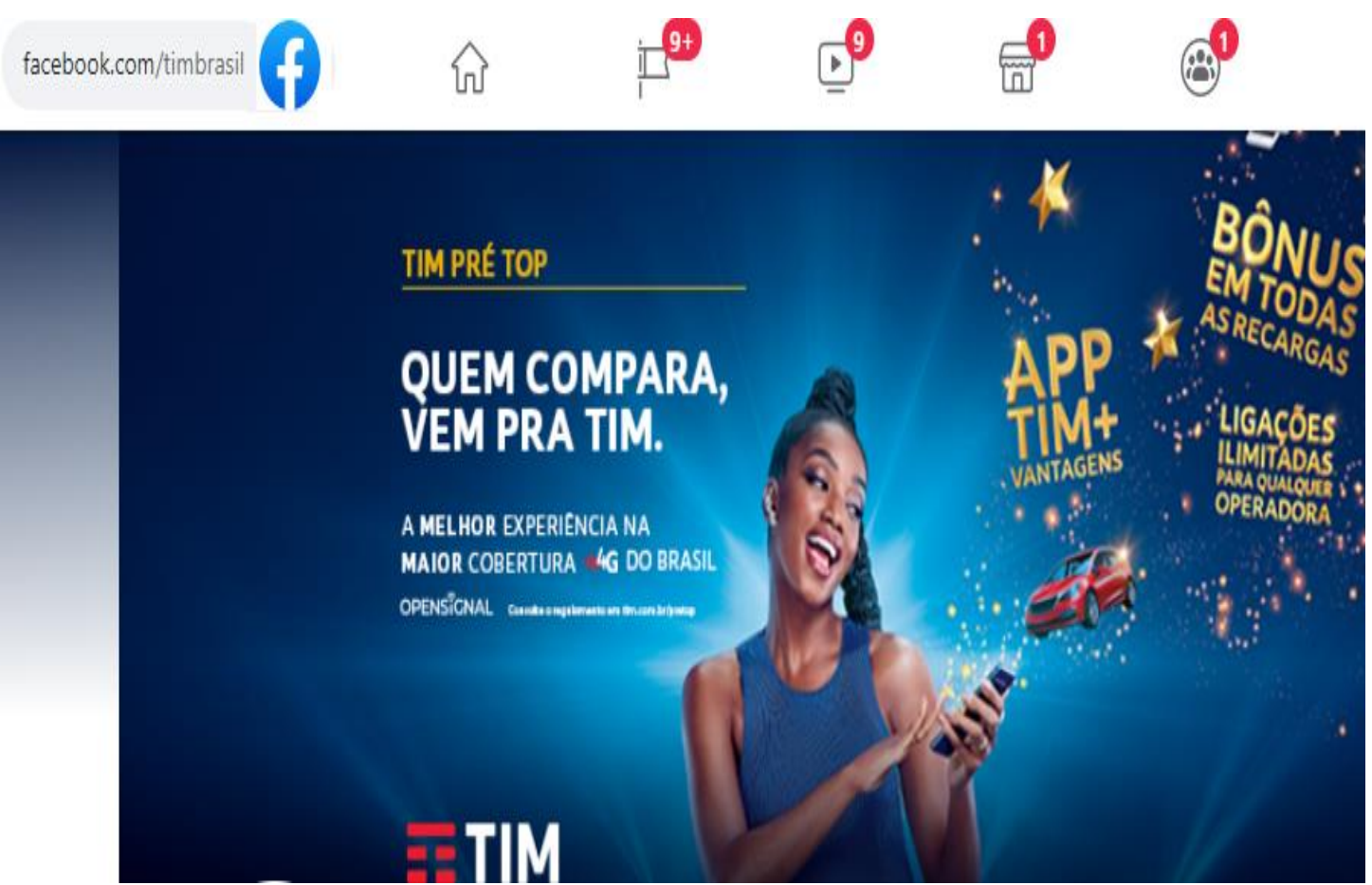

Fonte: Disponível em: https://www.facebook.com/timbrasil Acesso em 26 jun. 2021.

Na página do facebook da empresa aparece local para que os clientes enviem mensagem, mostram o número de curtidas e seguidores, no intuito de chamar mais gente para essa ação. Há link para o site, onde é possível interagir com a empresa por diversos canais e vias.

A TIM também explora o marketing de relacionamento por meio da empatia e "forma amigável de ser", promovendo em sua página do facebook, campanhas e lives com temas comemorativos, valorizando os envolvidos nestas datas especiais, se mostrando como uma organização que se importa com todos os públicos. 


\section{MAPEAMENTO DOS PROBLEMAS}

Analisou-se o comportamento e ponderações de alguns clientes da TIM, na página do facebook da empresa, e percebeu-se que, quase em unanimidade, eles reclamam do péssimo atendimento, da falta de retorno aos seus problemas e do alto preço dos pacotes tidos como "populares", das restrições dos aplicativos e do acesso ilimitado a alguns aplicativos, em especial, o "facebook".

Essas ponderações feitas neste canal prejudicam muito a imagem da empresa e se tornam um problema para ela, pois, conforme estudado, a globalização e a democratização do acesso aos diversos veículos de comunicação, impulsionados pela tecnologia, fazem com que a comunicação e a interação entre clientes e as empresas se estreitassem e se tornassem cada dia mais poderosas, exercendo impactos positivos e negativos para ambas as partes, pela proporção de indivíduos que atinge.

Isso nos alerta para o fato de que, se antigamente havia preocupação com a opinião dos clientes sobre uma determinada instituição, na atualidade ela se tornou o centro das atenções. Por isso, transmitir uma imagem positiva é imperativo para garantir destaque, crescimento e solidez da organização ante aos concorrentes, podendo assim, atrair e fidelizar novos adeptos.

\section{Imagem 2. Página da TIM no Facebook}

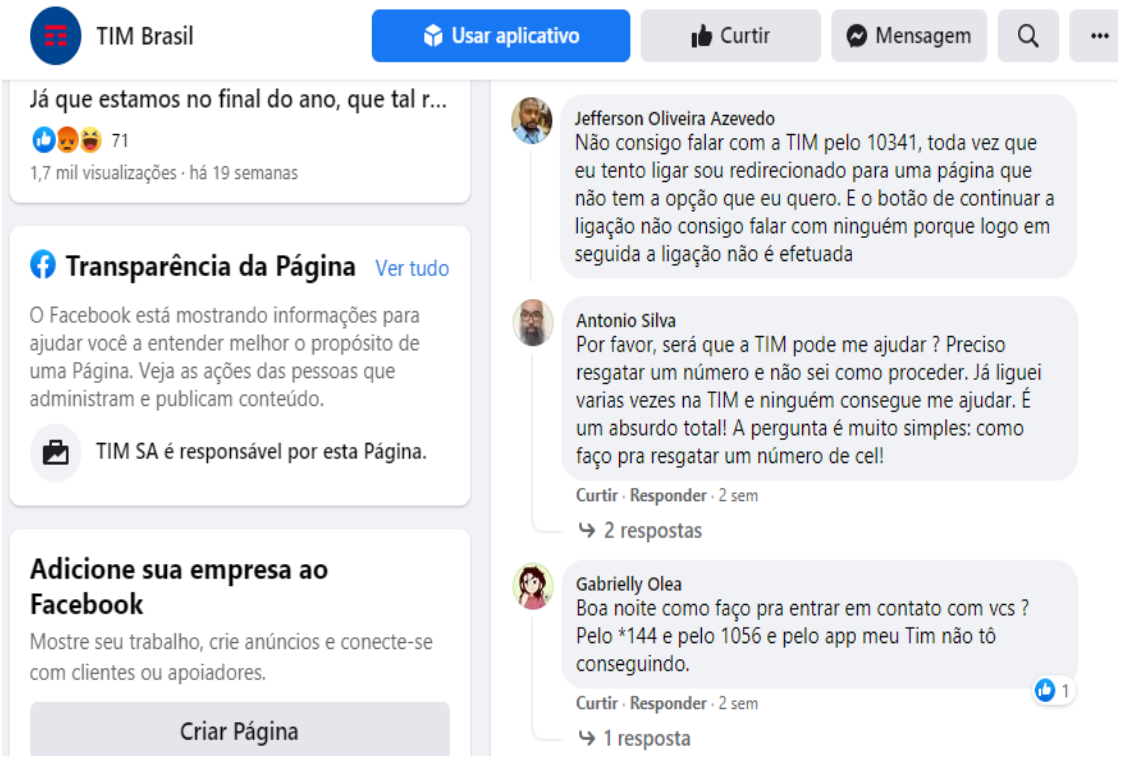

Fonte: Disponível em: https://www.facebook.com/timbrasil Acesso em 26 jun. 2021. 


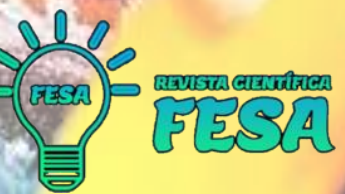

\section{PLANO DE INTERVENÇÃO}

A partir do problema, precariedade no atendimento, na comunicação e no relacionamento com os clientes através do canal de atendimento facebook (TIM), foi observado como causa, através do canal de comunicação Facebook da operadora TIM, que há uma discrepância homérica entre o que a empresa prega, como seus valores e a realidade praticada no atendimento, na comunicação e relação com os clientes nesta mídia.

Há, nitidamente, um descaso quanto às dúvidas, reclamações e sugestões dos clientes que comentam as postagens, fazem perguntas, sugerem alterações e ajustes, mas não há devolutiva por parte da empresa, atestando a falta de uma comunicação coesa e coerente, focada no padrão ascendente que possui o papel de interpretar essas falas e sugerir melhorias a gestão superior.

Por outro lado, teoriza-se que o marketing viral, como as propagandas "boca a boca", causa impactos gigantes na reputação de uma empresa, pois há muito mais credibilidade em algo dito por um amigo ou por uma pessoa que você conhece do que por uma empresa. Esse poder, na internet, é multiplicado, logo, é importante cuidar da comunicação e das informações prestadas a todos os envolvidos no processo a fim de garantir que os P's do Marketing Digital (propagação e personificação) sejam assegurados e tragam mais rentabilidade para a instituição.

Na visão de Drucker (2010):

O consumidor online é mais exigente, menos paciente e compartilha mais suas opiniões, principalmente as negativas, sobre experiências com as marcas. Conhecê-lo, saber seus hábitos, quais fatores motivam e quais desmotivam sua compra, é de fundamental importância para o sucesso de qualquer empresa (DRUCKER, 2010).

Ante a essa realidade, a empresa está ciente da amplitude do prejuízo que as perdas causadas pela propaganda negativa podem resultar, mas parece não se importar com isso, pois, como ela mesma afirma em relatos de sua identidade, o foco são vendas de telefonia comercial e pacotes combos-home (TV, telefone, internet por assinatura fixa). Talvez por isso não haja interesse em se investir no atendimento de qualidade e nem em desfazer essa imagem ruim que a empresa carrega por muito tempo já. 


\title{
POSSÍVEIS SOLUÇÕES
}

Nota-se que cada organização possui características particulares que as configuram como únicas, formando, assim, sua identidade. Por essa, razão, neste contexto, atrela-se: sua missão, visão e valores, que refletirão em sua imagem (cartão-postal), que o público interpretará.

Diante disso, se a identidade for robusta e atestar a credibilidade da empresa, a interpretação do público será a de uma organização séria, comprometida e confiável, o que contribuirá para que se inicie um relacionamento duradouro e positivo para ambas. Porém, caso o contrário ocorra, as relações passam a estremecer e definhar, prejudicando desastrosamente a empresa e gerando uma crise na imagem e reputação desta.

\begin{abstract}
A estratégia de comunicação consiste no plano da empresa para transmitir as notícias para seus públicos. A estratégia define quem são esses públicos, por que é importante comunicar-se com eles, quando e onde a comunicação deve acontecer, quem é o responsável pelas comunicações, o que deve ser dito e qual o vínculo com as metas comerciais (CORRADO, 1994, p. 34).
\end{abstract}

Essa visão mostra que o intuito da resolução de um problema, bem como a forma com a qual a empresa se porta ou se relaciona com seus clientes, está relacionada à visão e ao interesse da alta gestão, porque são eles que direcionam as outras áreas de foco da organização, que devem ter como princípio o lucro, que está atrelado diretamente ao cliente, sendo este a cereja do bolo e deve ser muito bem cuidado. Nesse sentido, indicaria que ocorresse, em curto prazo, um esforço para unificar a comunicação empresarial rumo a um único foco e objetivo: melhorar a imagem e reconquistar a credibilidade institucional ante ao público, garantindo, assim, mais visibilidade, maior adesão de novos assinantes e retenção dos já conquistados.

\section{CONSIDERAÇÕES FINAIS}

Ante ao relato apresentado, notou-se que é inicialmente pela comunicação que as organizações podem atingir público e se apresentar a ele, Neste sentido, cabe a elas cuidar de sua conduta e postura comunicacional, pois como afirmouse, a comunicação pode ser o estopim para gerar um atrito ou atrair os mais 


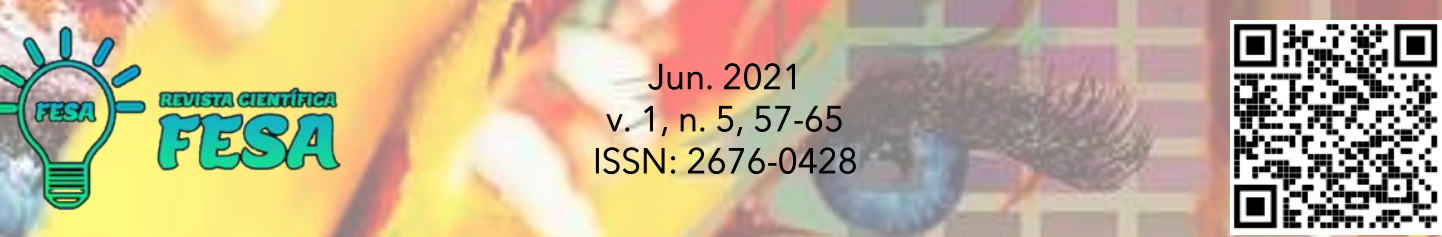

diversos interesses pela impressão que causou. Neste ponto que se percebe que a operadora TIM segue fracassando e precisa tomar medias urgentes para reverter esse quadro que a qualifica, cada vez mais, como uma organização que não traz segurança sobre o que oferta e nem oferece um suporte de qualidade aos seus clientes.

Como todo mundo gosta de ser bem tratado, infere-se que a utilização de um linguajar mais profissional, cortez, solícito e objetivo, seja a saída para desconstruir essa fama de que não se importam com os clientes. Para isso, será necessário disponibilizar, em médio prazo, mais canais de atendimento e suporte ao cliente de forma eficaz. Também serão necessárias mudanças nas condutas e objetivos das lideranças para que sondem de perto a realidade da empresa em todas as esferas comunicacionais, capacitando seus atendentes e outros colaboradores, a fim de que possam oferecer repostas positivas, seguras e que resolvam as dúvidas e queixas trazidas pelos clientes. Assim, somente comum trabalho em grupo e harmonioso, pode-se conduzir a empresa aos objetivos traçados em seu planejamento e fazer dela uma instituição forte e referência.

Sobre isso, Kunsch (1997, p. 115) afirmou que a atuação institucional coletiva fomenta a comunicação integrada para ela, pois:

[...] pressupõe uma junção da comunicação institucional, da comunicação mercadológica e da comunicação interna, que formam o composto da comunicação organizacional. Este deve formar um conjunto harmonioso, apesar das diferenças e das especificidades de cada setor e dos respectivos subsetores. A soma de todas as atividades redundará na eficácia da comunicação nas organizações (KUNSCH, 1997).

Por fim, baseado nas postagens feitas pelos clientes da TIM, no facebook, ficou nítido que sua conduta, nesta rede, influencia e potencializa a crise institucional por eles vivida neste momento, já que os consumidores reclamam desde a má qualidade no serviço ofertado, ao despreparo da organização para lidar com o seu consumidor, em especial, no que tange ao suporte.

Por esses relatos, os valores, a missão e a visão da organização não convergem com suas ações no âmbito virtual, o que acaba por intensificar a má impressão e o descrédito dos públicos com a marca, agravando a crise de imagem sofrida pela operadora. Dessa forma, torna-se clara a necessidade de planejar e de se posicionar nas redes sociais de maneira ética, coesa e coerente 
com os valores institucionais, representando o melhor desta, pois estes canais de comunicação são extensões da organização, portanto, credita os feitos dela.

\section{REFERÊNCIAS BIBLIOGRÁFICAS}

CORRADO, Frank M. A Força da Comunicação. São Paulo: Makron Books, 1994.

DRUCKER, P. F. Inovação e espírito empreendedor: práticas e princípios. São Paulo: Cengage Learning, 2010. 378 p.

OLIVEIRA, Elton, T de. Composto de Marketing Digital e Mídias Sociais. UCDB, Campo Grande, Mato Grosso do Sul. 2018

PIMENTA. Maisa, Helena e col. Marketing, Conhecimento, Informação e Comunicação em Tempos de Globalização. UCDB, Campo Grande, Mato Grosso do Sul. 2018

KUNSCH, Maria Margarida Krohling (Org.). Comunicação organizacional:histórico, fundamentos e processos. São Paulo: Saraiva, 2009.

\section{SITES CONSULTADOS}

SEBRAE. Marketing de relacionamento na venda online. Disponível em: https://www.sebrae.com.br/sites/PortalSebrae/ufs/mg/artigos/marketing-de-relacionamento-na-venda-online. Acesso 18/04/2021

TIM. TIM Brasil Apresentação Institucional 2ำ TRI 2017. Disponível em: file:///C:/Users/User/Downloads/Institucional\%20-\%202T17.pdf.Acesso $08 / 03 / 2021$

TIM. A TIM e a insatisfação de consumidores - uma possível crise de imagem. Disponível em: https://acervodigital.ufpr.br/bitstream/handle/1884/52926/TCC_A_tim_e_a_insatisfacao_de_consumidores.pdf;jsessionid. Acesso 10/03/2021

TIM. Facebook TIM Brasil. Disponível em: https://www.facebook.com/timbrasil / https://canaltech.com.br/empresa/tim-celular-sa/ Acesso 10/03/2021 